\title{
MENAKAR PELUANG DAN TANTANGAN PENYELESAIAN SENGKETA BISNIS FINTECH SYARIAH MELALUI LAPS
}

\author{
Siti Nurhayati ${ }^{1}$, Nurjamil ${ }^{2}$, \& Muhammad Haris Fadhillah ${ }^{3}$ \\ ${ }^{1,2, \& 3}$ Institut Manajemen Koperasi Indonesia (IKOPIN) \\ Email: sitinurhayati@ikopin.ac.id,nurjamil@ikopin.ac.id,mharisfadhillah@ikopin.ac.id
}

\begin{abstract}
ABSTRAK
Penelitian ini dilakukan untuk menguraikan peluang dan tantangan penyelesaain sengketa bisnis fintech melalui Lembaga Alternatif Penyelesaian Sengketa (LAPS) di Indonesia. Metode penelitian yang digunakan dalam penelitian ini pendekatan legal research dan pendekatan kualitatif yaitu dengan mengkaji sumber data primer dan sekunder terkait peraturan-peraturan tentang penyelesaian sengketa bisnis di Indonesia. Hasil penelitian menunjukan fintech berperan dalam mendorong perkembangan ekonomi masyarakat khususnya sebagai alternatif pembiayaan. LAPS berperan sebagai solusi penyelesaian sengketa para pelaku bisnis di Indonesia lembaga ini dipilih karena lebih efektif dan efisien, putusan bersifat final dan binding yang bertolak belakang dengan jalur litigasi yang terkesan memakan waktu dan biaya yang mahal. Peluang LAPS sangat besar mengungat maraknya bisnis dan pembayaran berbasis digital yang masih menyisakan banyak masalah hukum sementara LAPS khsusus fintech belum tersedia dimana LAPS menyediakan layanan yang sejalan dengan bisnis digital; penyelesaiannya yang bersifat win-win solution, yang sesuai dengan karakter dunia usaha, yang wajib mengelola resiko, termasuk resiko reputasi, resiko operasional dan resiko hukum. Sedangkan tantangan yang dihadapi LAPS pada fintech antara lain : Dualisme alternatif penyelesaian sengketa fintech bisa melalui LAPS dan bisa juga melalui Badan Penyelesaian Sengketa Konsumen (BPSK); Terbatasnya infrastruktur hukum jumlah transaksi fintech yang terus meningkat sejalan dengan potensi sengketa yangakan terjadi; Ketersediaan mediator dan arbiter LAPS sektor jasa keuangan.
\end{abstract}

Kata Kunci : Fintech, LAPS, Sengketa Bisnis.

\begin{abstract}
This research was conducted to outline the opportunities and challenges of resolving fintech business disputes through the Alternative Dispute Resolution Institute (LAPS) in Indonesia. The research method used in this research is a legal reasearch approach and qualitative approach that is to review primary and secondary data sources related to regulations on business dispute resolution in Indonesia. The results show that fintech plays a role in encouraging the economic development of the community, especially as an alternative to financing. LAPS serves as a solution to dispute resolution of business people in Indonesia this institution was chosen because it is more effective and efficient, the verdict is final and binding that is contrary to litigation lines that seem time-consuming and expensive costs. LAPS opportunities are very large for the rise of digital-based businesses and payments that still leave many legal problems while LAPS in fintech is not yet available where LAPS provides services that are in line with digital business; the settlement is a win-win solution, which is in accordance with the character of the business world, which is obliged to manage risks, including reputational risk, operational risk and legal risk. While the challenges faced by LAPS in fintech include: Dualism alternative fintech dispute resolution can be through LAPS and can also through the Consumer Dispute Resolution Agency (BPSK); Limited Legal Infrastructure The number of fintech transactions that continue to increase in line with the potential for disputes that will occur; Availability of Mediators and Arbitrators of LAPS Financial Services Sector.
\end{abstract}

Keywords: Fintech, LAPS, Business Disputes. 


\section{PENDAHULUAN}

Perkembangan teknologi yang pesat mempermudah masyarakat dalam melakukan sebuah transaksi keuangan (Hasanah \& Hanifah, 2020). Biasanya masyarakat hanya dapat melakukan transaksi keuangan secara langsung dengan datang ke kantor dari lembaga keuangan yang dituju, namun dengan adanya teknologi sekarang tersedia layanan-layanan keuangan berbasis digital yang mempermudah masyarakat untuk mengaksesnya (Aliyudin, 2020). Salah satu layanan keuangan digital yang sekarang diminati adalah financial technology atau sering disingkat dengan fintech. Fintech adalah sebuah layanan berbasis teknologi informasi sebagai bentuk inovasi layanan keuangan khususnya pada industri keuangan bukan bank, bandingkan dengan lembaga perbankan.

Saat ini, perusahaan fintech di Indonesia berdasarkan kategori produknya, diperkirakan perusahaan fintech di Indonesia ada sekitar 250 perusahaan. Mayoritas perusahaan fintech di Indonesia memiliki model bisnis berupa digital lending yaitu sebesar 55\% sebagaimana tabel berikut:

Tabel 1. Perusahaan Fintech Di Indonesia Berdasarkan Kategori Produk

\begin{tabular}{lc}
\hline \multicolumn{1}{c}{ Kategori Produk } & Presentase \\
\hline Digital Lending & $55 \%$ \\
\hline Capital Rising Crowfunding & $24 \%$ \\
\hline Digital Payment & $21 \%$ \\
\hline AI/MI/Big Data & $12 \%$ \\
\hline Tranding Capital Market & $6 \%$ \\
\hline Enterprise Tech For Finance & $6 \%$ \\
\hline Asset Management & $3 \%$ \\
\hline Enterprise Financial Management & $3 \%$ \\
\hline Insure Tech & $0 \%$ \\
\hline Personal Financial Management & $0 \%$ \\
\hline
\end{tabular}

Sumber: Cambrige Center for Alternative Finance (2019)

Kehadiran fintech ini mampu dijangkau oleh masyarakat luas karena dengan mudahnya akses internet yang sudah menyebar di hampir seluruh daerah Indonesia. Dengan proses yang cukup sederhana dibandingkan dengan lembaga keuangan seperti bank, maka fintech ini cukup diminati oleh masyarakat terutama pada produk digital lendingnya. Dengan banyaknya minat masyarakat dalam fintech ini tentunya masih memiliki resiko, seperti terjadinya sengketa atas tidak terpenuhinya kewajiban yang harus dibayarkan. Hal ini tentunya menjadi peluang dan tantangan bagi fintech dalam mengembangkan usahanya, penyelesaian sengketa ini dapat ditempuh melalui jalur litigasi dan non litigasi (lembaga alternatif penyelesaian sengketa), Penelitian ini mencoba mengurai peluang dan tantangan penyelesaian sengketa bisnis fintech melalui Lembaga Alternatif Penyelesaian Sengketa (LAPS) di Indonesia.

\section{TINJAUAN PUSTAKA}

Sebuah keniscayaan, bahwa tidak semua aktivitas bisnis berjalan seperti yang diinginkan, kadang pelaku bisnis menemui permasalahan yang tidak jarang berakhir dengan persengketaan. Menurut Maxwell J. Fulton sengketa bisnis adalah suatu hal yang muncul selama berlangsungnya proses transaksi yang berpusat pada ekonomi pasar. Sengketa muncul karena berbagai alasan dan masalah yang melatarbelakanginya, terutama karena adanya conflict of interest di antara para pihak (Inasyah, 2021). Fintech weekly sebagaimana dikutip Haddad (2017) menyatakan FinTech is a business that provides financial services through the use of software. Banking technology startups are typically created with the goal of disrupting incumbent financial systems and firms that rely less on software. LAPS atau Lembaga Alternatif Penyelesaian Sengketa merupakan sebuah lembaga yang dibentuk untuk memberikan pilihan bagi pelaku usaha dalam 
menyelesaikan sengketa bisnis melalui jalur non litigasi yang biasanya diinisiasi oleh asosiasi pada bidang bisnis tertentu, seperti LAPSPI untuk penyelesaian sengketa perbankan di Indonesia (Supriyatni \& Nurjamil, 2021).

\section{METODE PENELITIAN}

Metode penelitian yang digunakan dalam penelitian ini adalah deskriptif qualitative research, yaitu penelitian terhadap objek alamiah (kebalikan dari eksperimen) dimana peneliti merupakan unsur utamanya. Pendekatan yang digunakan adalah legal research dimana peneliti melakukan pengkajian terjadap sumber data baik primer maupun sekunder dalam bentuk peraturan perundang-undangan yang terkait penyelesaian sengketa bisnis dan peraturan perundang-undangan yang terkait platform bisnis fintech secara umum maupun fintech syariah yang kemudian dianalisis secara yuridis normatif sehingga diperoleh kesimpulan yang diharapkan.

\section{HASIL PENELITIAN PEMBAHASAN}

\section{Peran Fintech Dalam Perkembangan Ekonomi Masyarakat Di Indonesia}

Adanya teknologi yang diciptakan untuk mempermudah pekerjaan manusia semakin mengubah pandangan untuk bisa membuat pekerjaan menjadi lebih cepat, lebih praktis dan lebih mudah. Dalam perkembangannya teknologi telah merambat ke segala bidang mulai dari bidang sosial, politik, dan ekonomi. Perkembangan teknologi di bidang ekonomi dimulai dari revolusi industri 1.0 pada saat ditemukannya mesin uap yang menggantikan pekerjaan buruh di pabrik-pabrik inggris sampai era revolusi industri digital yang lebih dikenal sebagai revolusi industri 4.0. Era baru ini telah mengubah sistem ekonomi konvensional yang notabene berprinsip mempertemukan penjual dan pembeli di sebuah tempat (Marsudi \& Widjaja, 2019). Namun dengan adanya revolusi industri 4.0 ini maka para pihak tidak lagi diharuskan untuk ada dalam satu tempat yang sama ketika melangsungkan transaksi bisnisnya.

Dalam lembaga-lembaga keuangan teknologi digital juga sudah mulai diadaptasi seperti sms-banking, mobile-banking dan sebagainya. Sebagai lembaga yang disamping melayani produk-produk simpanan bank juga berperan penting dalam melayani kebutuhan masyarakat dalam bidang pembiayaan. Namun untuk dapat memenuhi persyaratan pembiayaan, calon penerima pembiayaan diharuskan untuk memenuhi syarat bankable. Tetapi didalam fintech syarat bankable tidak diperlukan dalam pengajuan pembiayaan oleh karena itu perkembangan fintech sangat pesat dewasa ini. Fintech merupakan singkatan dari financial technology yang pengertiannya adalah penggunaan kecanggihan teknologi dalam memberikan layanan keuangan sehingga terjadi efisisensi layanan secara maksimal (Rahmat \& Arifah, 2017).

Fintech sangat mendukung perkembangan ekonomi masyarakat dalam pembiayaan usaha melalui teknologi. Menurut Wasiaturrahma, Fintech juga diartikan sebagai inovasi berbasis teknologi modern dalam layanan keuangan yang praktis, mudah, nyaman dan ekonomis. Fintech memiliki keunggulan dibandingkan dengan layanan keuangan yang tidak berbasis online, diantaranya adalah sebagai berikut (Wasiaturrahma et al., 2019) lebih spesifik dapat pula dibandingkan dengan (Silalahi \& Hartati, 2020) :

\section{a. Meningkatkan Inklusi Keuangan}

Inklusi keuangan adalah upaya untuk meminimalisir hambatan sehingga terbukanya akses harga maupun non harga dalam layanan keuangan bagi masyarakat. Dengan adanya fintech, maka lembaga keuangan juga dapat meningkatkan efisiensi biaya pengadaan kantor ataupun pegawai, karena masyarat dapat mengakses secara online tanpa harus datang langsung. 
b. Meningkatkan Literasi Keuangan

Kemudahan akses internet di tengah masyarakat diharapkan dapat meningkatkan penggunaan fintech. Dengan meningkatnya penggunaan fintech, maka masyarakat akan semakin mengenal fitur-fitur dan kecanggihan teknologi keuangan.

\section{c. Meningkatkan Efesiensi dan Efektivitas}

Dengan adanya fintech, masyarakat dapat meningkatkan efisiensi biaya perjalanan dan dapat meningkatkan efektivitas transaksi yang dilakukan. Lembaga keuangan juga dapat menurunkan biaya pegawai, biaya kantor, serta biaya administrasi dalam setiap transaksi.

d. Meningkatkan Pertumbuhan Ekonomi

Fintech dapat mempertemukan antara investor dengan masyarkat yang membutuhkan dana untuk mengembangkan usaha atau mendirikan sebuah usaha. Dengan berkembangnya usaha masyarakat, maka dapat meningkatkan tingkat produksi serta membuka lapangan pekerjaan secara luas sehingga dapat meningkatkan pertumbuhan ekonomi.

Fintech menjadi populer di Indonesia karena memiliki berbagai alasan sebagai berikut (Amalia et al, 2020):

a. Penggunaan internet dan telpon pintar yang massif sehingga mengharuskan transaksi daring.

b. Anggapan tentang sisi praktis yang dimiliki fintech dibanding layanan konvensional.

c. Digitalisasi bisnis yang cukup meluas.

d. Palaku start-up bisnis yang memerlukan platform dan layanan yang sederhana.

e. Media sosial yang digunakan menjadi alasan perkembangan dengan adanya perkembangan data yang diakses untuk menjadi bahan risk analysis.
Selain kemudahan-kemudahan pembiayaan yang ditunjukan fintech pada masyarakat, sebagai negara hukum Indonesia juga telah membuat berbagai aturan dalam kegiatan fintech. Peraturan terkait transaksi fintech di Indonesia saat ini sudah diatur pada beberapa peraturan terkait, seperti Peraturan Otoritas Jasa Keuangan (POJK) Nomor 77/POJK.01/2016 tentang Layanan Pinjam Meminjam Uang Berbasis Teknologi Informasi (LPMUBTI), Peraturan Bank Indonesia (PBI) Nomor 18/40/PBI/2016 tentang Penyelenggaraan Pemprosesan Transaksi Pembayaran (PTP), Peraturan Bank Indonesia (PBI) Nomor 19/12/PBI/2017 Tentang Penyelenggaraan Teknologi Finansial, UU No: 8 Tahun 1999 Tentang Perlindungan Konsumen, dan Undang-Undang Nomor 11 Tahun 2008 tentang Informasi dan Transaksi Elektronik. Khusus untuk transaksi berbasis syariah berlaku fatwa DSN MUI terkait, yaitu DSN MUI 117/2018 tentang Layanan Pembiayaan Berbasis Teknologi Informasi Berdasarkan Prinsip Syariah yang terus membutuhkan input agar berkembang ke arah yang lebih baik seperti dilakukannya studi banding dengan negara lain yang juga mempraktikkan bisnis fintech syariah (Alfaris et al, 2019). Regulasi terkait menjadi perlindungan bagi masyarakat atas maraknya fintech illegal, perlindungan data pribadi, dan lainnya dimana problematika peraturan khsusunya mengenai fintech syariah juga masih memerlukan penyelesaian yang intensif (Habibunnajar \& Rahmatullah, 2020). Keterbatasan OJK dalam mengatasi permasalahan yang terjadi dalam bisnis fintech menuntut diundangkannya regulasi yang lebih sepsifik sekelas Undang-undang sehingga para pelaku bisnis ini mendapatkan perlindungan dan kepstian secara hukum. (Dakum \& Asari, 2020)

\section{Peran LAPS dalam penyelesaian sengketa fintech di Indonesia}

Seperti halnya lembaga keuangan lainnya fintech syari'ah pun seringkali mengalami perselisihan yang menyebabkan sebuah sengketa antara investor dan 
penerima pembiayaan. Sengketa biasanya dipicu dari ketidakpatuhan pada kontrak yang telah di sepakati oleh para pihak. Sengketa merupakan situasi dan kondisi dimana orang-orang saling mengalami perselisihan yang bersifat faktual maupun perselisihan-perselisihan yang ada pada presepsi mereka saja. Sengketa terjadi karena tidak ada titik temu antara pihakpihak yang bersengketa (Rahmat \& Arifah, 2017).

Dalam penyelesaian sengketa fintech masih banyak berbagai kekurangan sumber hukum yang mengatur penyelesaian sengketa fintech. Penyelesaian sengketa dapat ditempuh melalui jalur litigasi dan non litigasi. Litigasi adalah sistem penyelesaian sengketa melalui lembaga peradilan yang menghasilkan keputusan win-lose solution bagi pihak yang bersengketa. Jalur non litigasi ini merupakan sistem penyelesaian sengketa melalui non peradilan yaitu diantaranya dapat melalui negosiasi, mediasi, konsiliasi, arbitrase, penilaian ahli, dan penyelesaian melalui perantara debt collector (Rahmat \& Arifah, 2017).

Dalam hal terjadi permasalahan sebetulnya UU ITE telah memberikan ruang bagi penyelesaian sengketa perdata melalui jalur litigasi ataupun non litigasi dalam hal ini melalui ADR/APS atau melalui Lembaga Alternatif Penyelesaian Sengketa. Lembaga penyelesaian sengketa telah banyak diambil para pelaku bisnis dalam menyelesaikan sengketa yang dihadapi. Karena jalur litigasi dapat menjadi hal yang buruk bagi perkembangan bisnis yang dijalankan. Karena mahkamah agung masih tergolong lama, mahal dan beresiko tinggi serta sulitnya dalam memutuskan hasil putusan. Ditambah dengan maraknya mafia hukum yang bisa saja memenangkan salah satu pihak dengan cara yang tidak adil menambah ketidakpercayaan para pelaku bisnis dalam menyelesaikan sengketa yang dihadapi melalui lembaga litigasi.

Banyak sekali resiko yang dihadapi jika menyelesaikan sengketa melalui lembaga litigasi yang disebabkan oleh berbagai hal seperti kerahasiaan yang tidak terjaga oleh pengadilan yang bersifat umum dan terbuka sampai hasil putusan yang diakhiri dengan menang-kalah dan bisa mengakhiri hubungan bisnis. Penyelesaian sengketa diluar pengadilan melalui LAPS lebih diminati karena lebih efektif dan efisien. Banyak model LAPS yang bisa ditempuh mulai dari negosiasi, mediasi, konsiliasi dan arbitrase (Supriyatni \& Nurjamil, 2021).

Oleh karena itu, penyelesaian sengketa melalui lembaga litigasi konvensional atau secara offline tidak tepat untuk digunakan. Pasal 29 huruf e Peraturan OJK nomor 77/POJK.01/2016 juga mengamanatkan penyelesaian sengketa harus dilakukan secara sederhana, cepat dan biaya terjangkau. Proses pembiayaan yang tergolong online dan banyak aktivitasnya dilakukan via internet, sehingga membutuhkan proses penyelesaian sengketa yang lebih cepat, mudah dan murah. OJK sebaiknya membentuk Lembaga APS online yang khusus menangani sengketa bisnis fintech. (Hariyani \& Serfiyani, 2017)

\section{Peluang dan Tantangan Lembaga Alternatif Penyelesaian Sengketa}

Sebagai sebuah Lembaga alternatif, LAPS menawarkan model penyelesaian sengketa bisnis yang tentu saja berbeda dari dari penyelesaian pada umumnya. Dalam hal ini yang dihaapkan adalah terselesaikannya sengketa bisnis dan tetap terjaganya iklim dan kondusifitas usaha sehingga eksistensinya menjadi sangat penting Ketika dikaitkan dengan esensi bisnis yang umumnya adalah berorientasi profit (profit oriented) (Nurjamil et al, 2019). Peluang yang dapat dimanfaatkan LAPS pada fintech untuk membantu perkembagan bisnis, antara lain:

a. Era revolusi industri 4.0 yang masih berkembang dengan maraknya bisnis $e$ commerce dan masih membutuhkan sebuah lembaga untuk menyelesaikan sengketa yang dihadapi ketika terjadi sebuah sengketa. 
b. LAPS tergolong lebih murah, cepat dan sederhana dalam menyelesaikan sengketa dibandingkan lembaga litigasi, serta maraknya praktek mafia hukum yang menyebabkan akibat buruk pada bisnis yang terkena sengketa.

c. Kecocokan dalam proses penyelesaian sengketa dalam era digital yang harus dilakukan secara efektif dan efisien.

d. Mediasi yang dilakukan secara tertutup dengan penyelesaian yang bersifat winwin solution, yang sesuai dengan karakter dunia usaha, yang wajib mengelola resiko, termasuk resiko reputasi, resiko operasional dan resiko hukum. (Mulyati, 2016)

Sedangkan tantangan yang masih dihadapi oleh LAPS pada fintech antara lain:

a. Tardapatnya dualisme dalam penyelesaian sengekata alternatif, yaitu LAPS sebagaimana diamanahkan oleh POJK dan Badan Penyelesaian Sengketa (BPSK) sebagaiman diatur dalam Undang-undang Perlindungan Konsumen. Dalam hal ini menjadi satu permasalahan tersendiri bagi masyarakat yang mencari keadilan, kepastian sekaligus juga kondusifitas dalam kegiatan bisnis.

b. Infrastruktur yang masih sangat terbatas menjadi tantangan tersendiri dimana saat ini LAPS hanya terpusat di Jakarta, padahal dengan semakin meningkatnya jumlah pengajuan penyelesaian sengketa harusnya berbanding lurus dengan bertambahnya fasilita layanan dan infrastruktur dimana perwakilan LAPS harus terdapat di seluruh daerah di Indonesia sehingga sejalan dengan prinsip aksestabilitas atau mudah nya akses sebagaimana diamanahkan dalam Pasal 28 ayat (2) POJK No. 61/POJK.07/2020.

Terbatasnya jumlah Arbiter dan Mediator pada LAPS Jasa Keuangan yang eksistensinya sangat menentukan kualitas LAPS tersebut, sehingga jumlah mediator dan arbiter harus sebanding dengan rasio banyaknya sengketa yang diajukan. (Kharisma, 2021)

\section{KESIMPULAN}

Fintech berperan sebagai pendukung perkembangan ekonomi masyarakat dalam pembiayaan usaha melalui teknologi. Fintech merupakan salah satu inovasi di bidang finansial yang mengacu pada teknologi modern. Inovasi tersebut bertujuan untuk memperkenalkan kepraktisan, kemudahan akses, kenyamanan dan biaya yang ekonomis sehingga mempermudah penggunanya. LAPS berperan sebagai solusi penyelesaian sengketa para pelaku bisnis di Indonesia lembaga ini di pilih karena lebih efektif dan efisien. Keputusan dalam LAPS bersifat final dan pasti selesai, berbeda dengan melalui jalur litigasi, putusan oleh mahkamah agung terbilang cukup lama, sekain itu biayanya juga mahal. Apalagi dengan maraknya mafia hukum yang bisa saja memenangkan salah satu pihak dengan cara yang tidak adil yang akan menambah ketidakpercayaan para pelaku bisnis menyelesaikan masalahnya. Peluang yang dapat dimanfaatkan LAPS pada fintech untuk membantu perkembagan bisnis seperti; maraknya bisnis e-commerce dan masih membutuhkan sebuah lembaga untuk menyelesaikan sengketa yang dihadapi ketika terjadi sebuah sengketa; LAPS lebih murah, cepat dan sederhana; Kecocokan dalam proses penyelesaian sengketa dalam era digital yang harus dilakukan secara efektif dan efisien; penyelesaiannya yang bersifat win-win solution, yang sesuai dengan karakter dunia usaha, yang wajib mengelola resiko, termasuk resiko reputasi, resiko operasional dan resiko hukum. Sedangkan tantangan yang dihadapi LAPS pada fintech antara lain : Dualisme alternatif penyelesaian sengketa fintech bisa melalui LAPS dan bisa juga melalui Badan Penyelesaian Sengketa Konsumen (BPSK); Terbatasnya Infrastruktur Hukum Jumlah transaksi fintech yang terus meningkat sejalan dengan potensi sengketa yangakan terjadi; Ketersediaan Mediator dan Arbiter LAPS Sektor Jasa Keuangan. 


\section{DAFTAR PUSTAKA}

Alfaris, Maulana Reyza., Mursida, Muhammad Waliyum., \& Syahroni, Moch Irfan Dwi. 2019. Model Regulasi Financial Technology Syariah Dalam Kerangka Hukum Indonesia: Studi Perbandingan Malaysia Dan Inggris. Legislatif, 3(1), p. 73-96.

Aliyudin, Rizal Sukma. 2020. Peran Financial Technology Dalam Meningkatkan Penerimaan Pajak Di Indonesia. Jurnal Akuntansi Keuangan Dan Sistem Informasi, 1(1), p. 56-67.

Amalia, H. N., Ramdani, M. G., Ashiddiq, M. R., Sulistiyani, I., \& Lokania. 2020. Penyelesaian Sengketa dalam Peer to Peer Lending (Pinjam Meminjam Online). Lontar Merah, 2(1), p. 148153.

Dakum \& Asari, Aang. 2020. Urgensi Pembentukan Undang-Undang Fintech sebagai Upaya Legalisasi Penyelesaian Sengketa Transaksi Fintech di Indonesia. Borobudur Law Review, 2(1), p. 1-15.

Habibunnajar, Rizal., \& Rahmatullah, Indra. 2020. Problematika Regulasi Pinjam Meminjam secara Online Berbasis Syariah di Indonesia. Jurnal Legal Reasoning, 2(2), p. 120-134.

Hadad, Muliaman D. 2017. Financial Technology (FinTech) di Indonesia. Di akses pada 20 Januari 2020 dari : http://www.ibs.ac.id/img/doc/MDH\%20 \%20FinTech\%20IBS\%20June\%202017 .pdf

Hariyani, Iswi., \& Serfiyani, Cita Yustisia. 2017. Perlindungan Hukum Dan Penyelesaian Sengketa Bisnis Jasa PMTekfin. Jurnal Legislasi Indonesia, 14(3), p. 345-358.

Hasanah, H., \& Hanifah, A. 2020. Implementasi Model Pengembangan Pengelolaan Koperasi Simpan Pinjam (KSP). Jurnal Muhammadiyah Manajemen Bisnis, 1(1), p. 37-47.
Inasyah, Dini. 2021. Penyelesaian Sengketa Bisnis. Di akses pada 20 Agustus 2021 dari

https://www.pphbi.com/penyelesaiansengketa-bisnis/

Kharisma, Dona Budi. 2021. Tantangan LAPS Sektor Jasa Keuangan Sebagai Alternatif Penyelesaian Sengketa di Sektor. Prespektif, 26(3), 216-220.

Marsudi, Almatius Setya., \& Widjaja, Yunus. 2019. Industri 4.0 dan Dampaknya Terhadap Financial Technology Serta Kesiapan Tenaga Kerja di Indonesia. Jurnal Ikraith Ekonomika, 2(2), P. 1-10.

Mulyati, E. 2016. Penyelesaian Sengketa di Luar Pengadilan dalam Rangka Perlindungan terhadap Nasabah Bank. ADHAPER Jurnal Hukum Acara Perdata, 2(1), 115-133.

Nurjamil., Nurhayati, Siti., Agung, Ahmad., \& Risnaningsih, Ine. 2019. Model Penyelesaian Sengketa Pembiayaan Bermasalah Pada Bank Wakaf Mikro Berbasis Pesantren. Res Nullius Law Jurnal, 1(2), p. 85-97.

Rahmat, Tri., \& Arifah, Risma Nur. 2017. Penyelesaian Sengketa Kredit Macet Pinjam Meminjam Uang Berbasis Teknologi Informasi (Financial Technology). Journal of Islamic Business Law, 1(3), p. 1-14.

Silalahi, Rizal., \& Hartati, Ni Luh Wulandari. 2020. Keunggulan Komparatif Antara Fintech Lending Dan Kredit Mikro Perbankan. Perbanas Review, 5(1), p. 25-38.

Supriyatni, Renny., \& Nurjamil. 2021. The Existence of Alternative Dispute Settlement Institutions Indonesian Banking (LAPSPI) In the Islamic Banking Non Performance Loan. Journal of Legal, Ethical and Regulatory Issues, 24(1), p. 1-14.

Supriyatni, Renny., \& Nurjamil. 2021. The Urgency of Handling Non-Performing 
2022, Jurnal Tabarru' : Islamic Banking and Finance 5 (1) : 63 - 70

Financing in Sharia Banks in the

Development of Indonesian Sharia

Economics. PADJADJARAN Jurnal

Ilmu Hukum (Journal of Law), 8(1), p. 26-46. 